\title{
Psychotropic Drugs: The Excessive, Yet Inconclusive Treatment for Child Victims of Domestic Violence by United States Institutions
}

\author{
Robert Burke \\ Rollins College, Winter Park, USA \\ Email: 1bobbyburke@gmail.com \\ Received 8 April 2016; accepted 23 May 2016; published 26 May 2016 \\ Copyright (C) 2016 by author and Scientific Research Publishing Inc. \\ This work is licensed under the Creative Commons Attribution International License (CC BY). \\ http://creativecommons.org/licenses/by/4.0/ \\ c) (i) Open Access
}

\begin{abstract}
Domestic violence is a serious issue in the United States and, at its most extreme, domestic violence can result in broken families and ruin the lives of many individuals. In many cases, moreover, domestic violence can have a detrimental effect on children if they are involved. When children are involved in domestic violence they are often the recipients of the worse, often resulting in state intervention in order to secure the child's safety until the problem is resolved. This can be challenging for children. Indeed, children who need state intervention because of domestic violence enter a system that is already overwhelmed with cases of abandonment, neglect, abuse and even mental health problems. This puts, in many cases, otherwise very healthy children into a system that deals with the rehabilitation of children with serious health issues. This, in turn, exacerbates the dilemma in terms of rehabilitation on all the children involved. In some cases, in turn, state intervention for children of domestic violence can actually result in these healthy children developing disorders such as attachment disorder, and developing distrust with their overall worldview.
\end{abstract}

\section{Keywords}

Psychotropic Medications, State Intervention, Behavioral Health Services, Big Pharmaceuticals

\section{Introduction}

Domestic violence occurs in three ways: intimate partner violence, spousal directed violence, and violence

How to cite this paper: Burke, R. (2016) Psychotropic Drugs: The Excessive, Yet Inconclusive Treatment for Child Victims of Domestic Violence by United States Institutions. Open Journal of Social Sciences, 4, 189-197. 
involving children [1]. Despite how domestic violence occurs in the household, if children are involved they can typically take the most negative effect of this domestic violence. If children are involved in domestic violence, despite the circumstances, the state defines this as child maltreatment or neglect. In a national study by the U.S. Department of Health and Human Services, "approximately 903,000 children were identified by child protective services (CPS) as victims of abuse or neglect in 2001" [2]. Unfortunately, the problems sometimes get worse. Children often display challenging behavioral problems after they are separated from their family, and this only increases their anxiety. Therefore, my argument then focuses on the critical analysis of how child protective services, which are often funded by federal grants and taxes, handle mental rehabilitation of children who suffer from domestic violence and need state intervention. In the course of my investigation, I will focus on the fundamental problem and risks associated with the treatment of children with behavioral problems in the child protection services, namely, the use of psychotropic drugs to treat children who suffer from abuse. I contend that psychotropic drugs for children should be a last resort treatment approach because their use often results in more long term harm than good to the child.

Douglas S. Diekema (2008) suggested that children under eighteen and some elderly are the most common examples of those who lack complete rationality. However, in this paper I focus only on the former: children who lack the rational ability to take actions based on critically evaluated deliberations. Of course, the responsibility of choice for children typically falls on the parents or legal guardians of the child. However, what is best medically for a child might not always be within the morals of the patient's guardian. Diekema (2008) offered the example of vaccines and their ideological objectors to show how sometimes states rights to intervene on behalf of a child trump parental authority. Diekema (2008) contends that the doctrine of parens patraie establishes that "the state is to act as 'surrogate parent' when necessary to protect the life and health of those who cannot take care of themselves, including children” [3]. By extension, I contend that domestic violence and child abuse also qualify as situations in which parental rights should not be absolute. Diekema (2008) centered his focus on the judicial and ethical standards currently employed with state intervention policy. In doing so, he drew attention to the "Threshold for Intervention" (138) and provided alternative criteria for intervention, which I will apply to the situation of domestic violence and child abuse. Although Diekema's distinction and criteria were used for children in potentially life-threatening situations like cancer treatments and immunizations, I use similar reasoning in this argument to further the discussion in terms of domestic violence and child abuse.

Earlier, I identified some situations in which the state might have the rights and a duty to intervene in situations involving vulnerable children. The specific situations in which a state can intervene in cases involving children vary depending on the circumstances, but most situations are outlined by The Administration on Children, Youth and Families (ACYF) in their National Child Abuse and Neglect Data System (NCANDS), which are compiled from state and federal child protective services agencies.

First, NCANDS defines a victim as "any child for whom the state determined at least one maltreatment was substantiated or indicated" (21). The FFY 2014 data from NCANDS indicate the national number of recorded victims of abuse or neglect was 702,000 [xii]. NCANDS also provided a three-fold description of maltreatment types included in these numbers. The most common type was neglect- 75 percent of victims; physical abuse17 percent; and sexual abuse -8 percent of victims [1].

\section{Methods}

Clearly, there is a great need for intervention from competent child protective agencies in the case of child abuse, neglect, and/or sexual abuse. Based on the 2014 national estimate, the types of care provided to the children represented by these statistics range from a staggering 23 percent or 147,462 receiving foster care services. Moreover, there are expenses associated with placing children in foster care in a group home, or residential treatment center [4]. Additionally, many children in foster care have special health care needs that the child's state welfare agency must provide for. The medical needs of the children predominately come in three ways: physical, dental and behavioral health needs [1]. Physical and dental needs are mostly objective medical treatments and thus require a treatment that will fix the problem with little deliberation or disagreement between medical professionals. But in this paper, I focus only on the latter, behavioral health needs.

In the academic sphere as well as society in general, behavioral health needs have become synonymous with mental disorders, which The Center for Disease Control and Prevention (2016) described as serious changes in the way children typically learn, behave, or handle their emotions, and which cause distress and problems getting through the day [5]. These problems can be exacerbated when children enter the state foster care system. 
However, Kamala D. Allen and Taylor Hendricks (2016), of the Center for Healthcare Strategies, linked the trauma of neglect and the removal from home as potential factors leading to challenging behavior. Allen and Hendricks (2016) found that according to Medicaid data, children in foster care represent three percent of children on Medicaid, which accounted for 15 percent of total children on Medicaid using behavioral health services. Even more concerning was that Allen and Hendricks (2016) claimed that these children represented 13 percent of those on Medicaid receiving psychotropic medications, rendering children in state run foster care four times more likely to receive psychotropic drugs than other children [6].

These alarming statistics should raise concern on multiple levels: First, the drugs are given to children, and even worse, the state might be the authority that is recommending them. Second, psychotropic drugs are rarely effective ways to treat the behavioral disorders displayed by children who are the victims of abuse.

So, first, it is important to understand what psychotropic drugs are and what they do. Pierre Schulz and Thierry Steimer (2000) defined psychotropic medication this way: "A psychotropic drug can be described according to the way in which it influences receptors, transporters, and enzymes, i.e., the cellular sites of its pharmacological actions" (178). Another characteristic of the drugs is that they vary in their ability to be selective. For example, Clozapine acts on several cell-membrane receptors and transporters at once; in fact, ten separate modes of action are affected, giving it the classification of a "dirty" drug [7]. However, psychotropic drugs have a more selective route in the brain, a common target being the serotonin transporter blockers, or selective serotonin reuptake inhibitors (SSRIs) [7]. But, Schulz and Steimer are quick to object to the true "selectiveness" of SSRIs by arguing that body systems, which sub-serve many higher brain functions, are still influenced by the drugs and there are adverse effects and inherent risks associated with using them [7].

\section{Results}

The reality of institutionalized drug use — and some of the associated risks — can best be understood by considering primary accounts of children who have lived it. For example, ABC's 20/20 investigation on the drugging of foster children, which was based on a two-year investigation orchestrated by the Government Accountability Office (GAO), studied the GAO's macro level investigation focusing on foster children in Florida, Massachusetts, Michigan, Oregon, and Texas. The GAO investigation (2011) found foster children in these five states were prescribed psychotropic drugs at rates 2.7 to 4.5 times higher than were non-foster children on Medicaid in 2008. In addition, these states spent over $\$ 375$ million for psychotropic prescriptions provided through fee-forservice programs to foster and non-foster children [8]. In Texas, 58.2 percent of foster children in the age range of 13 - 17 were prescribed psychiatric medication, compared to just 11 percent of non-foster children, meaning a child under state care was five times more likely to be prescribed psychiatric medications. Moreover, Texas foster children were 52 times more likely to be prescribed five or more psychotropic medications, essentially a cocktail of drugs to be taken at the same time. Michigan followed, at 14 times and Oregon at 12 times more likely to prescribe their foster youth over five psychiatric medications at one time [8].

Interestingly, the investigative report-Generation Meds, focused on a micro-level investigation of psychotropic drugs and their side effects, based on primary accounts of youth in Child Protective Services (CPS). In the case of Brook, for example, a seven-year-old, 43-pound child who was prescribed five different psychotropic drugs for mental disorders, the child began to exhibit serious anger outbreaks and her foster parents were told to take her to a mental health clinic. What was the mental health clinic's solution? Not surprisingly, more drugs, including the commonly prescribed anti-schizophrenic drug Seroquel. Weeks later, the medications failed to improve Brook's violent and angry outbreaks, and her mother claimed they continued to worsen. The changes in medication continued, and reached an astonishing ten changes in just four months [9]. Similarly, Kayla, Brook’s older sister, experienced her sister's fits of rage first hand. She commented, “I don't know how they could possibly help children, if all they do is just give the child meds. It makes children feel out-of-place” [Generation Meds]. The girl's foster mother, Lisa, who felt she had no choice, and who was concerned the state would take her foster children, continued with the doctors' instructions. She recounted, "we were told to put our faith in the system. That was it." [Generation Meds]. Kayla added, "that's how sad it is, the meds make you feel like tantrums are good and to get the anger out. But no, it doesn't.” [Generation Meds]. Lisa finally decided to not trust the system; instead she went to an outside, private doctor who was stunned by the footage of Brook's tantrums. She did so, not because of the tantrums themselves, but because of the obvious contributing factor: the drugs she was being prescribed. His first course of action was to begin weaning Brook off of the medications and focusing on "alternate" responses like therapy and communication [9]. 
Clearly, Brook's case shows the impact drugs can have on the previously mentioned subsystems of brain activity that are affected by psychotropic drugs. In this example, side effects resulted in rage, anger, and further confusion for the parent and child. Not only does it give example to the adverse effects these drugs can have, it provides evidence of how minimally active the foster system was in aiding the parent and child in treatment. First, the parent and child were experiencing pain, and instead of the system collaborating with all parties involved to find a solution, she was continually told to trust the system. However, the system continued to peddle seven-year-old Brook ten different medications, including one for schizophrenia, in just four months [9]. Stories like Brook's illuminate a two-fold problem: first is the inherent problem of side effects, which stem from psychotropic medications. The second problem stem from attempting to provide alternative remedies for behavioral health issues. There is an additional problem with framing other remedies as alternative, namely, doing so presupposes that medication should be the first step concerning behavioral health, which I argue is a flawed preconception.

The American Academy of Child And Adolescent Psychiatry's (AACAP) A Guide for Community Child Serving Agencies on Psychotropic Medications for Children and Adolescents (2012), stated that the organization is "composed of over 7,500 child and adolescent psychiatrists and other interested physicians whose members actively research, evaluate, diagnose, and treat psychiatric disorders..." [3]. This organization's definition of psychotropic medicines includes those that are taken for the purpose of improving the emotional and behavioral health of a child or adolescent diagnosed with a mental health condition [10]. This public service agency established a section of its recommendations titled Prescribing Basics, and in it, they stated: "the benefit from the medicine must be evaluated against the potential unwanted side effects, both biological and psychosocial, when considering whether a medication should be prescribed [10]. Side effects can occur in two ways: long term and short term. Since psychotropic drugs have been around only since the late 1980s, it's inconclusive what long-term effects they may have. This problem should speak for itself, especially in the context of developing children.

As far as short term effects, a follow up report on the GAO investigation provided vivid primary accounts of the effects psychotropic medications have had on the foster youth. Ke'onte, an eleven-year-old who was prescribed a cocktail of drugs after his abusive foster relative, Diane Sawyer attested after interviewing Ke'onte, "...beat him with belts, switches, and extension cords-which not only left him with the physical scars on his body, but understandably, with anger and despair" [11]. During his time with the state foster care system, he was placed in six different homes in just four years and he was "treated" with a variety of mind-altering drugs including: a mood stabilizer Depakote; a stimulant, Vyvanse; the antidepressant Lexapro; Clonidine for ADHD; and the antipsychotic Seroquel [11]. Luckily, Ke'onte was able to join a loving family, a luxury that only one in ten foster youths ultimately obtain. In the realm of his new family, his parents Carol and Scott Cook were determined to put an end to his use of meds. Their attempt to do so landed the new family in an unfamiliar location, using the services of a private doctor and child therapist who claims Ke'onte does not have ADHD, nor does he have bipolar disorder. During his interview, while reflecting on a video of his actions while on the drugs, Ke'onte confided: "I feel great pity for that kid" [11].

These primary accounts reveal different examples of short-term side effects. Primarily concerning how the medication made the individual feel and subsequently act, but also the more physiological consequences like weight gain and the possible increased risk of diabetes. These reflections also give insight into the feelings and subsequent actions after removing meds from their daily ritual, including: the feel of "freedom," feeling "in control of myself," and even boosting one's ability to succeed in the classroom [11]. To shed light on this, I will use the American Academy of Child and Adolescent Psychiatry's (AACAP) more theoretical definition of Psychotropic medicines; taken for the purpose of improving the emotional and behavioral health of a child or adolescent diagnosed with a mental health condition. Thus, the AACAP argues that the best approach in psychopharmacology is essentially syndromal. Schulz and Steimer discussed what syndromal means by giving some examples: Internists know that they either substitute for a missing compound (e.g., insulin), attack an infectious agent (i.e., antibiotics), or "cheat the body" (e.g., induce a dysfunction in normal physiology in order to influence a symptom) [7]. Drugs used for cardiac insufficiency decrease blood volume, increase the muscular capacity of the myocardium, modify vascular resistance, lower heart rate, etc.” [7] Thus, when an internist prescribes medication they have a clear idea of what the body is experiencing and are thus better situated to recommend medication based on cardiac insufficiency. On the contrary, psychiatrists might be more likely to prescribe medications based on emotional and behavioral symptoms and speculative outcomes. The reason internists are better situated 
in recommending treatments to their patients is because their remedy is direct. Schulz and Steimer continue their distinction by stating "in psychopharmacology, direct links are often made from receptor or transporter to symptoms, without an intermediate analysis of which physiological functions are also modified as a result of medication" [7]. These authors caution against this type of linear logic concerning mechanisms of disorders, specifically thinking in terms of a direct link between actions of psychotropic medications at a receptor and the changes in symptoms it provides. Thus, psychotropic drugs are too often prescribed based on psychiatric symptoms, rather than higher brain dysfunctions. Based on this, Schulz and Steimer argued for a shift in paradigm: psychotropic drugs should be framed as modifying normal higher brain functions, rather than merely treating symptoms, which they do only secondarily. In their analysis, Schulz and Steimer called for a new classification of psychiatric disorders based on the elaborate development of psychological and physiological concepts in the neurosciences [7].

I think we should apply this analysis to the children interviewed who reported and described the side effects of drugs prescribed through the foster care system. The horrifying feelings and subsequent actions described by the children can be attributed to the gap in logic that Schultz and Steimer argued that psychiatrists often operate under while prescribing. Side effects are a result of not understanding the vast network of higher brain functioning [7]. Thus, medicating with psychotropic drugs has become a game of trial-and-error with the brain until the symptoms of the real underlying problem are curtailed back to "normal".

While it is fair to say that children in foster care may experience increased mental and behavioral issues, this doesn't entail that their problems are different from those of other children, nor does it justify the need for giving them powerful medications. ABC's investigative report interviewed Dr. Charles Zeanah, Director of Child and Adolescent Psychiatry at Tulane University, sheds light on the diagnostic protocol: "the general consensus is that when you're treating young children, you always try behavioral intervention before you go to medication" [11]. By extension, foster systems are rarely able to provide the true, formal and comprehensive services that children with behavioral issues should be entitled. Surely symptoms like anxiety, irritability and behavior issues are symptoms diagnosed, at one point or another, in any lifestyle. It's safe to assume that these symptoms, especially in a child, would increase in the event of abuse, neglect, and irregularity concerning their parents and home-life. In effort to reduce the effects of the scars of trauma and the symptoms that arise as a result, medications are being used like Band-Aids for a cut that desperately needs stitching. In the case of foster children, behavioral intervention seems to be considered too time-consuming and thus, too expensive. Because the time and money required for the general consensus is seen as too much, the institutions that intervene for the reason to protect children, are the very institutions that are supplying and coercing children into taking mind-altering substances as treatment.

Additionally, Dr. Jeffrey Thompson, Chief Medical Officer for Medicaid in the state of Washington, said, "Nobody gets up in the morning to overdose kids... Kids get aggressively diagnosed and sometimes we look for the easy solution, which is a pill over psychotherapy or better parenting” [9]. The fundamental problem in Dr. Thompson's explanation is two-fold: First, he admits to the systematic over-diagnosing of kids, and then asserts that the easy solution is a pill rather than psychotherapy or better parenting. This is precisely the problem in the foster care system. The chief medical officer for Medicaid in Washington State believes symptom-based prescribing of psychotropic drugs offers a form of solution over therapy and better parenting, presumably, just as Dr. Thompson might prefer stiches to a Band-Aid, in the event he slices his finger open, he seems to accept that the practice of prescribing medications first and behavioral interventions second is acceptable. I argue that, in many cases, most children need, and would prefer, competent therapy services to a pill. Similarly, Dr. George Fouras, a child psychiatrist and co-chairman of the AACAP takes my position even further by stating: "We are trying to put a nice shiny term that sounds (as if) 'oh, we're just restraining the kid.' (when) really what you are doing is just knocking them out to make them less of a problem for you” [9].

To move the discussion further into how Medicaid-sponsored medicating of foster children affects adults who grew up within it, the case of Tyrone Obasekiis illuminating. Obaseki entered the foster care system at just two months old. As an adult, he earned Bachelor's in Sociology from Texas A\&M and a Master's in counseling from Prairie View. Obaseki is quickly attested to his "hellish" experience in an interview with Corrina Rachel (2014). Obaseki stated, "The way I felt in CPS? I felt like an animal, because every little behavior that I displayed, it was written down as if I was bi-polar or schizophrenic" [12]. Obaseki went on to talk about how the environment he endured in child protective services exacerbated the issues he had to deal with because of abuse, neglect, and trauma. He continued, "if you go into CPS and you do not take your medication, the first step is re- 
straint, more trauma. And then psych hospitals; at the age $8 \mathrm{I}$ had already been placed in two psych hospitals, causing even more trauma" (Overmedicating Foster Care Children For Money). The mindset that children take away from this is that there is something inherently wrong with them. They have encountered traumatic experience after experience, are often forcibly given drugs as restraints from expressing their feelings and emotions, and rarely are they given any affection [12]. Not only is the labeling that occurs psychologically damaging to a child, the restraining and forcing of medication he speaks of are disrespectful and infringe on a child's autonomy. The negative impacts of the supposed safe haven for the neglected indicate numerous new measures must be implemented.

Notably, Diekema referred to the doctrine of parenspatraie, which establishes that the state has a duty to act as a surrogate parent in order to protect the life and health of those who cannot take care of themselves. However, the preponderance of evidence I have presented suggests that the best interests of the state in securing the health and life of children, may not always be the best, and sometimes they are just the most convenient, for the state, when Diekema's “threshold for intervention” theory is used to analyze the effectiveness of state intervention in the realm of child abuse and domestic violence.

\section{Discussion}

The essay until this point has largely been concerned with how state institutions choose to treat the mental instabilities of children who've experienced abuse and neglect. Although the evidence suggests that it is often otherwise, the current standard for state intervention requires a guardian to act so to always make the decision most favorable to the child. However, the competing interests often complicate what is best for the child. The doctor's interest may seem like the most logical, but a child also has an interest, and the child is the one that might be affected emotionally and physically [2]. In many of the cases mentioned above, the best interest of the child has defaulted to the most beneficial economic interest of the state. Diekema suggested that "it's less about identifying the best medical treatment for a child, but rather identifying a harm threshold below which parental decisions will not be tolerated" (140). Although he proposed that the state operate in terms of intervening in parental sovereignty when warranted, it serves good purpose for the evaluation, and his recommendations offer a possible new model for Medicaid and Child Protective Services to abide by. Primarily, Diekema states, the question practitioners and guardians of foster care children should ask first: "does the decision made significantly increase the likelihood of serious harm as compared to other options?” (141). This standard could be used when children are diagnosed with any disorder. The pure subjectivity concerned with the classification of a disorder would render the ability to prescribe drugs with harmful side effects much more difficult. Based on the harm threshold, a doctor would have to explain why the mind-altering side effects and possibility of harm necessarily outweigh the potential benefits associated with the medication. Considering the medical community's little knowledge of how psychotropic drugs affect someone long-term, especially with regard to their long-term effects on the developing mind of a child, these drugs should encounter an immediate challenge [2].

Further, Diekema’s Harm Threshold, based on Feinberg's harm principle, suggests an eight-fold set of criteria on which the state should ground their justification for state intervention. To narrow the scope, I apply only four of his criteria to this argument. These four criteria are: a) Is the harm imminent, requiring immediate action to prevent it? b) Is the intervention that has been refused of proven efficacy, and therefore, likely to prevent harm? c) Do its projected benefits outweigh its projected burdens significantly more favorably...? d) Would any other option present serious harm to the child in a way that is less intrusive to parental autonomy and more acceptable to the parents? [2]. Immediately, if only these four criteria were to be applied, it is clear that the parties involved with the child's health would be required to assess the potential harm, helping to increase accountability on behalf of the doctor and pharmaceutical companies.

Next, it is important to consider whether the treatments suggested for children of abuse have been proven effective. According to the AACAP, when a medication is considered "off-label," the FDA has not yet approved the medication. FDA Black Box Warnings, on the other hand, indicate that the medications have been FDA approved, but require special attention and caution regarding the potentially dangerous or life-threatening side effects. Moreover, Selective Serotonin Reuptake Inhibitors (SSRIs) carry a black box warning that they may cause suicidal ideation or behavior, although the most recent review of the evidence is not conclusive that SSRIs increase suicidal behavior. Families should work in consultation with their child's physician or other mental health professional to develop an emergency action plan, called a "safety plan” in case their child exhibits any suicidal 
behavior [10]. Even within the foster care system and on Medicaid, children are being prescribed drugs that haven't even been approved by state regulating institutions. The very institutions in place to protect us from inconclusive and unsubstantiated medical practices, like these very drugs, are in fact yielding when it comes to pharmaceutical companies, whom the AACAP suggests "may not choose to dedicate the necessary resources to seek FDA approval" [10]. An additional problem is that the AACAP itself, which is presumably a major source of information for parents, doctors, and patients, is almost defending the inherent problem of Black Box medications by advocating for a "safety plan" in the event a child exhibits suicidal behaviors. By applying Diekema's second rule regarding proven treatments to the examples above, the incompetence shown by these organizations would certainly encounter friction when trying to pass medications without proven evidence on the effects.. When considering behavioral medications, many would consider suicide as a reason to provide these medications in the first place; however, the very medications advertised to protect against such erratic behavior could actually increase the potential for harmful actions by a child.

In discussion of the final threshold, other options should be considered before options that might present serious harm to the child. Other, less intrusive forms of treatment like therapy, communication, and a competent trustworthy guardian are available to children of abuse, but the states are often unwilling to provide the necessary resources to these children for them to obtain these less intrusive, and less harmful forms of treatment. However, holding practitioners, the FDA, pharmaceutical companies, and guardians accountable to the standards of the harm threshold might provide a reliable mechanism for addressing the problems that perpetuate children "feeling like bricks are on their head" [Generation Meds].

This plan provides better avenues for addressing the systemic and institutionalized "easy" fix that has pillaged the foster care system. Unfortunately, the current way of dealing with the overwhelming lack of competent parents has become a system that may or may not be less competent and more problematic to a child's short-term needs, as well as long term needs. However, the system is just as vulnerable and misguided as the youth under its supervision. In his novel Saving Normal (2013), Allen Frances suggests diagnostic inflation, psychiatric fads, and the paramount promoter behind both—pharmaceutical drug marketers—as the driving factor of widespread, unjustified adoption. For example, in the late 1980s and early 1990s, SSRI anti-depressants, particularly Prozac, became a best seller and in the years following came new SSRIs like Zoloft, Paxil, and Celexa, and each showed promise for eager pharmaceutical companies [13]. The profitability of these easy-to-use drugs quickly became evident. Frances stated about these drugs that

The marketing of these easy-to-use drugs was closely tied to the marketing of what were (according to the drug companies) easy-to-make psychiatric diagnoses. Soon the SSRIs were also prescribed for panic disorder, generalized anxiety, social phobia, OCD, PTSD, eating disorders, premature ejaculation, and compulsive gambling, and as a general pick-me-up [13].

The same profit and marketing potential brought a new round of SSRIs or antipsychotics like Risperdal, Zyprexa, and Seroquel, and with their seemingly less problematic side effects, they were beating sales records around the country. However, Frances also attested that the schizophrenia market, to which SSRIs were originally purposed, was too narrow for the record-breaking sales. Something else must have been at play. With a 60 billion dollar-a-year advertising and promotional budget, which is double the research budget, pharmaceutical companies have capitalistically defaulted to the business of marketing, rather than focusing on the research needed for the relatively small number of patients who truly need medicine [13]. Frances further described the influential reality of 60 billion dollars by declaring:

In recent decades, the drug companies have efficiently hijacked the medical enterprise by exerting undue influence on the decisions made by doctors, patients, scientists, journals, professional associations, consumer advocacy groups, pharmacists, insurance companies, politicians, bureaucrats, and administrators [13].

This army of trusted, educated and influential professionals chooses to believe the sales representatives of pharmaceutical companies and just like that they return to their profession and knowingly or not, begin marketing for the company.

Frances continued;

The best way to sell psychotropic pills is to sell psychiatric ills. Drug companies have many methods of doing this: TV and print media adverts; co-opting most physicians' continuing medical education (often provided at the most expensive restaurants and the nicest resorts; doctors in training and medical students 
come cheaper—a pizza will do); bankrolling professional associations, journals, and consumer advocacy groups; invading the Internet and social networking sites [13].

In my estimation, pharmaceutical companies have brought profit-only driven corporations into the formerly sacred space healthcare industry. Similar to the drugs they push, the side effects of a money hungry healthcare industry have been detrimental to society. In light of this profit-driven system, Susan Cullen and Margaret Klein (2008) emphasized the importance of physicians and parents respecting a patient's autonomy due to a patients lack of knowledge on the subject. They claimed:

When knowledge is power, ignorance is slavery. Unknown to a patient, a doctor that operates for profit only, has restricted the freedom to make meaningful choices. In this way, the doctor has discounted the patient's ability to reason and make decisions, and in this way, treated a patient with disrespect [14].

Although just a thought experiment, these authors have defined the immense responsibility doctors have in their position regarding healthcare. A doctor's unique position of power carries with it a responsibility within the medical profession for an outstandingly trustful, moral, and ethical character because their knowledge is essential to their patients' health and well-being. Thus, because patients trust their doctors, they are vulnerable if the doctor acts contrary to their benefit. By extension, pharmaceutical companies, given their widespread reach, should call for an even more heightened sense of responsibility to patients. However, the seemingly unregulated, profit-driven privilege they operate in, has fostered an environment where money is more compelling than the ethics. The ability billions of dollars has to affect the logic and rationale of the public at large has become insurmountable to the point of exploiting a vulnerable population, the youth. Money has created a lawless territory for big pharmaceutical companies to do what they please. Ethics and morals yielding to money and greed is far from a new dynamic in the United States, but bringing the fist of justice to those who exploit children would be fitting in the case of patients who have suffered child abuse and neglect. Fining the pharmaceutical conglomerates is not the fist of justice, and is often considered a meager loss in their abundant profit. Instead, the United States must hold individuals accountable for the actions of corporations. That being said, if a CEO doesn't know the under working of the company he is the head of, the CEO better start. These forces are too powerful for a fine, too greedy for morals, and too widespread to not be held strictly accountable for their actions.

\section{Conclusion}

Overall, identifying the main threat to the already overwhelmed foster care system is essential to identifying and beginning to address the various problems that have compounded the current ultra-problematic environment. In addition, we also must consider the underlying socioeconomic problem that is prohibiting the funding of treatments with proven effects. It is hard to believe that in the United States of America cannot find the funds to improve the efficiency and accountability of its own foster care and child protective services systems. Psychotropic drugs may seem to be the cheap option, but the treatments they provide have little evidence of actually improving the behavioral and emotional problems related to this population. Using psychotropic drugs as symptom based treatment is neglectful in itself. Until a child can asses, consult with doctors on their own, and learn about their behaviors and emotions with the help of competent psychologists or mental health professionals, they should not be prescribed psychotropic medications. When the psychotropic treatment is compared to more progressive treatments like therapy, the cost might be more expensive at the beginning for therapeutic treatments, but the reoccurring costs lessen with time and increase the effectiveness of treatment in the long run. Tax payers who fund the operations of institutions like child protective services should consider how the government is handling their youth and appropriating their taxes. The paradigm shift needed regarding treatments for children of abuse and neglect must change from the question "can we afford it?” to the question, "can we afford not to?” [11].

\section{References}

[1] U.S. Department of Health \& Human Services, Administration for Children and Families (2014) Administration on Children, Youth and Families, Children’s Bureau (2016) Child Maltreatment, 76.

[2] Bragg, H.L. (2003) Child Protection in Families Experiencing Domestic Violence. National Clearinghouse on Child Abuse and Neglect Information, 7. https://www.childwelfare.gov/pubpdfs/domesticviolence.pdf

[3] Diekema, D.S. (2008) Parental Refusals of Medical Treatments: The Harm Principle as Threshold for State Intervention. In: Munson, R., Ed., Intervention and Reflection Basic Issues in Medical Ethics Eighth Edition, Thomson Higher 
Education, California, 138-142.

[4] Lord, S. (2014) Foster Children HHS Could Provide Additional Guidance to States Regarding Psychotropic Medications. United States Government Accountability Office, Washington DC, 1-8.

[5] Division of Human Development and Disabilities (2016) Children’s Mental Health Basics. Centers for Disease Control and Prevention, DeKalb County.

[6] Allen, K.D. and Hendricks, T. (2015) Medicaid and Children in Foster Care. The State Policy and Reform Center, 2.

[7] Schulz, P. and Steimer, T. (2000) Psychotropic Medication, Psychiatric Disorders, and Higher Brain Functions. Dialogues in Clinical Neuroscience, 2, 177-182.

[8] Kutz, D.G. (2011) Foster Children, 3-14. http://www.gao.gov/assets/590/586570.pdf

[9] Abdelmalek, M., Adhikari, B., Koch, S., Diaz, J. and Weinraub, C. (2013) New Study Shows U.S. Government Fails to Oversee Treatment of Foster Children with Mind-Altering Drugs. ABC News, ABC News Network.

[10] Metz, P., Chenven, M., McGinty, K., Hodas, R.G., Klaehn, L.R. and Larson, J. (2012) A Guide for Community Child Serving Agencies on Psychotropic Medications for Children and Adolescents, American Academy of Child and Adolescent Psychiatry, 4-13.

http://www.aacap.org/app themes/aacap/docs/press/guide for community child serving agencies on psychotropic medications for children and adolescents 2012.pdf

[11] American Broadcasting Company, Sawyer, D. and Alfonsi, S. (2011) 20/20 Generation Meds. YouTube Video Sharing Company, ABC News.

[12] Obaseki, T. (2014) Overmedicating Foster Care Children for Money, Foster Care Abuse Documentary. Interview, performed by Corrina Rachel (Target Public Media, 2014), Web.

[13] Allen, F. (2013) Saving Normal: An Insider’s Revolt against Out-of-Control Psychiatric Diagnosis, DSM-5, Big Pharma, and the Medicalization of Ordinary Life. William Morrow, Print, New York.

[14] Cullen, S. and Klein, M. (2008) Respect for Patients, Physicians, and the Truth. In: Munson, R., Ed., Intervention and Reflection Basic Issues in Medical Ethics, 8th Edition, Thomson Higher Education, California, 155. 